\title{
Práticas e ferramentas gerenciais de apoio a integração e coordenação de projetos
}

Practices and tools to support the building integration and coordination

\section{MELISSA BELLAN \\ MÁRCIO MINTO FABRICIO}

Arquiteta e Urbanista, graduada pelo Centro Universitário de Belas Artes de São Paulo, mestre em Arquitetura e Urbanismo pelo Programa de Pós-Graduação em Arquitetura, Urbanismo e Tecnologia da Escola de Engenharia de São Carlos - USP.

Engenheiro Civil, graduado pela Universidade Federal de São Carlos, mestre em Arquitetura pelo Programa de Pós- Graduação em Arquitetura, Urbanismo e Tecnologia da Escola de Engenharia de São Carlos - USP, doutor em Engenharia Civil pelo Programa de Pós-Graduação em Engenharia de Construção Civil da Escola Politécnica da Universidade de São Paulo, professor do Programa de PósGraduação em Arquitetura e Urbanismo da Escola de Engenharia de São Carlos - USP.

melissabellan@gmail.com

marcio@sc.usp.br

\section{Resumo}

O desenvolvimento do projeto de edifícios é caracterizado pela fragmentação em diferentes etapas e em diferentes empresas envolvidas na formulação do programa, projetos de arquitetura, projetos de engenharia, etc. Neste contexto a coordenação de esforços é fundamental para o sucesso do projeto. O objetivo deste trabalho é descrever as principais práticas e ferramentas gerenciais de apoio à atividade de coordenação de projetos de edifícios e o método de pesquisa consistiu de estudos de caso junto ao processo de integração e coordenação de projetos desenvolvidos em duas construtoras e incorporadoras de edifícios que atuam no estado de São Paulo. Como principal resultado o trabalho apresenta uma síntese de práticas gerencias e quadros analíticos, caracterizando procedimentos e ferramentas de coordenação que podem ser utilizados para formação e aprimoramento de coordenadores de projeto.

Palavras-chave: coordenação de projetos; práticas e ferramentas de apoio; projeto integrado. 


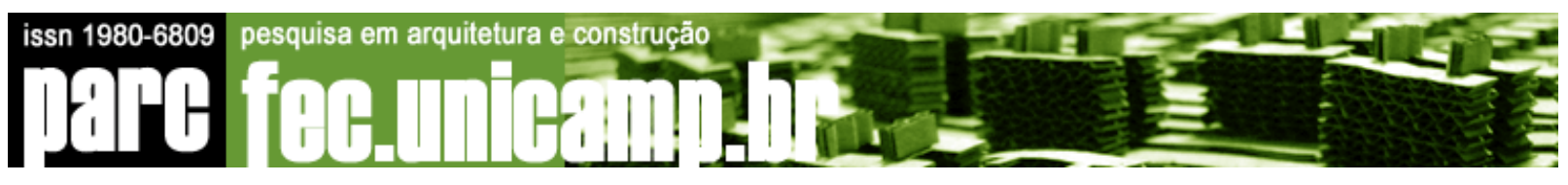

Abstract

The design in Architecture, Engineering and Construction is characterized by fragmentation at different stages and different companies involved in the formulation of the program, architecture projects, engineering projects, etc. In this context the coordination of efforts is fundamental for the success of the design process. The objective of this work is to describe the main managerial practices and tools to support the building design coordination activity and the research method applied were case studies considering the process of integration and coordination of projects developed in two companies that are builders and developers of buildings of the State of São Paulo. Therefore, the main result of the study is a synthesis of management practices, characterizing managerial procedure and tools of coordination that can be used for training and improvement of project coordinators.

Keywords: coordination of projects; practices and tools of support; integrated project. 


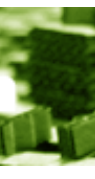

\section{Práticas e ferramentas gerenciais de apoio a integração coordenação de projetos}

\section{Introdução}

$\mathrm{Na}$ literatura diferentes autores abordam o projeto em suas diversas dimensões e abrangência como Processo de Projeto (Design Process) ou Processo de Desenvolvimento de Produto. A principal distinção entre essas duas denominações diz respeito a abrangência do processo envolvido. Enquanto a abordagem de Processo de Projeto costuma dar ênfase as atividades dos especialistas ligados ao projeto do produto (projeto de arquitetura, estruturas, instalações e etc., no caso da construção de edifícios), a abordagem de desenvolvimento de produto é voltada ao processo desde o planejamento do produto, projeto do produto e do seu processo de produção, manutenção e descarte, ou seja é focada no ciclo de vida do empreendimento. Segundo Machado e Toledo (2008, p.1) "O desenvolvimento de produto corresponde a uma série de atividades organizadas com o objetivo de transformar um conceito de produto em um produto acabado tangível".

Para Rozenfeld et al (2006), o processo desenvolvimento de produtos - PDP compreende atividades interconcatenadas de planejamento, concepção, desenvolvimento, validação e detalhamento de soluções, desenvolvidas de forma incremental para se chegar em especificações e projetos de um novo produto e/ou de um novo processo de produção.

Este processo, afirmam os autores, é pautado pelas demandas de mercado, as possibilidades e restrições tecnológicas e as estratégias competitivas da empresa responsável pelo novo produto.

O PDP envolve necessariamente diferentes profissionais e a montagem de equipes multidisciplinares. Para Back, et al. (2008) o desenvolvimento de produto é um processo de transformação e geração de informações e deve ser efetuado por uma equipe multidisciplinar e integrada.

$\mathrm{Na}$ construção e incorporação de edifícios o desenvolvimento de um novo produto é fragmentado em diferentes partes, sobre diferentes responsabilidades. Assim, é comum que promotores imobiliários, com apoio de um profissional de arquitetura, assumam a montagem do negócio, a definição e incorporação do terreno e a montagem de um programa de necessidades. Posteriormente o promotor contrata os projetos de arquitetura e engenharia que são desenvolvidos por empresas diferentes e contemplam o projeto do produto, 
envolvendo conceito do projeto, definições espaciais e volumétricas e desenvolvimento das soluções tecnológicas (Fabricio, 2009).

Neste modelo, bastante tradicional no setor, o desenvolvimento de produto é limitado ao projeto de produto e as soluções de produção são relegadas à empresa responsável pela construção do edifício que deve planejar e detalhar o processo produtivo do mesmo.

Assim, o desenvolvimento de edifícios pode ser considerado fragmentado e com múltiplas interfaces entre diferentes agentes que precisam ser coordenadas de forma efetiva (Fabricio, 2002).

\section{Objetivos e Método}

Para ser exercida com efetividade a coordenação de projetos envolve uma série de atividades concatenadas e a utilização de ferramentas gerenciais de apoio.

O presente artigo tem como objetivo analisar como empresas construtoras e incorporadoras de edifícios realizam a coordenação de projetos, mapeando e descrevendo as principais práticas e ferramentas gerenciais de apoio à atividade de coordenação de projetos. O objeto de pesquisa foi o processo de coordenação de projetos de edifícios desenvolvidos através da modalidade de construção e incorporação.

Este trabalho foi desenvolvido no contexto de uma pesquisa em nível de mestrado, consistindo de uma revisão bibliográfica das principais atividades de coordenação de projeto e apresenta o desenvolvimento de dois estudos de caso, junto a duas grandes empresas construtoras e incorporados de edifícios do estado de São Paulo. Para uma maior compreensão da prática de Coordenação de Projetos de Edifícios foi feita a opção pelo estudo de caso, no qual o foco se manteve no modo de executar as atividades, bem como nas ferramentas de apoio mais utilizadas para solucionar os problemas, de uma maneira rápida e eficaz. Nos estudos de caso foram observados as fases e atividades de coordenação de projetos, compatibilização de desenhos, controle do fluxo de informações e dos prazos, bem como as e ferramentas gerencias utilizadas. A análise dos casos compreendeu comparações entre os dois casos estudados e destes com o mapeamento das fases de projeto e atividades de coordenação descritos na literatura, especialmente em Melhado et al. (2005).

Como principais resultados o trabalho apresenta uma síntese de diversas práticas e de ferramentas gerencias e um conjunto de quadros analíticos que caracterizam de forma 
detalhada algumas práticas de coordenação e podem ser utilizados para formação e aprimoramento de coordenadores de projeto.

\section{Revisão Bibliográfica}

\subsection{Coordenação de Projetos}

Segundo Melhado et al. (2005, p.71): "[...] a coordenação de projetos é uma atividade de suporte ao desenvolvimento do processo de projeto voltada a integração dos requisitos e das decisões de projeto. A coordenação deve ser exercida durante todo o processo de projeto e tem como objetivo fomentar a interatividade na equipe de projeto e melhorar a qualidade dos projetos assim desenvolvidos".

A coordenação é fundamental para a obtenção da qualidade no processo de PDP e, por essa razão, é relevante a sua adequada atuação durante todo este processo.

Coates et. al. (2004) afirmam que a coordenação de projetos é a chave para melhorar a performance do processo de projeto e integrar os especialistas envolvidos.

Para Franco e Agopyan (1993), a coordenação do processo de projeto objetiva: solucionar as interferências entre projetos elaborados pelos diferentes projetistas; - conduzir as decisões a serem tomadas durante o desenvolvimento dos projetos; - controlar a qualidade dos projetos, de forma que estes sejam executados em consonância com as especificações e requisitos pré-estabelecidos (custos, prazos e especificações técnicas).

Além de garantir que as soluções técnicas desenvolvidas pelos projetistas das diferentes especialidades sejam compatíveis entre si, a coordenação de projetos deve, ainda respeitar as necessidades e objetivos dos clientes e considerar a cultura construtiva da empresa construtora da obra.

\subsection{Atividades de Coordenação de Projetos}

No "Manual de Contratação de Serviços de Arquitetura e Urbanismo" da Associação Brasileira dos Escritórios de Arquitetura - ASBEA (2000) há a afirmação que o projeto é formado por um conjunto de atividades e dividido nas seguintes fases: - concepção; execução; - coordenação; - gerenciamento de projetos. Igualmente aponta que a coordenação é uma atividade sobreposta às fases, de concepção e execução e que abrange 
não só o projeto arquitetônico, mas todas as atividades multidisciplinares que lhe são inerentes.

As principais tarefas da coordenação de projetos estão relacionadas à organização e ao planejamento do processo de projeto e à gestão e coordenação das soluções de projetos desenvolvidos. E para Saram e Ahmed (2001) a coordenação está dividida em três categorias: planejamento, organização e controle.

Para a AsBEA (2000), as atividades de coordenação de projetos abrangem as seguintes tarefas:

- Compatibilizar dados e informações.

- Coordenar as soluções dos projetos e consultorias intervenientes na concepção e execução da obra.

- Verificar as interfaces entre os projetos complementares, o projeto arquitetônico e as exigências do contratante.

- Compatibilizar os projetos complementares e estes com o arquitetônico.

Para conduzir bem a coordenação de projetos, é de extrema importância o conhecimento do processo de projeto, pois permite o planejamento das atividades de coordenação de projetos e do fluxo de informações geradas nesses projetos.

Com esse embasamento Melhado et. al, (2005, p.76) afirmam que:

A sistematização das atividades de coordenação depende de como se estrutura o processo de projeto e da sua tipificação em fases, atividades, verificações, análises críticas e validações.

Assim, visando proporcionar uma melhor compreensão do trabalho desempenhado pela coordenação de projetos, Melhado et al. (2005, p.77), desenvolveram uma tabela de atividades, necessárias em cada fase de desenvolvimento do projeto - QUADRO 1.

Nesse sentido, se torna relevante que o processo de projeto seja conhecido e mapeado, para propiciar o planejamento e o fluxo de informações. Contudo, para que isso aconteça, são necessárias reuniões entre as equipes, consultores e empreendedores, para serem elaboradas as fases do processo de projeto, bem como para que essas fases sejam cumpridas nos prazos estabelecidos. 


\begin{tabular}{|c|c|}
\hline FASES DE PROJETO & ATIVIDADES DE COORDENAÇÃO \\
\hline Idealização do Produto & $\begin{array}{l}\text { 1. Formulação conjunta com o empreendedor do programa de Necessidades } \\
\text { 2. Análise das restrições legais de uso e ocupação para terreno em estudo } \\
\text { 3. Identificação das especialidades de projeto, qualificações dos projetistas e escopos } \\
\text { de projeto a contratar } \\
\text { 4. Estimativa dos recursos necessários ao desenvolvimento do projeto } \\
\text { 5. Organização, realização e registro de reuniões de coordenação de projetos } \\
\text { 6. Análise das propostas de prestação de serviços e assessoria para contratação dos } \\
\text { projetistas }\left({ }^{*}\right) \\
\text { 7. Obtenção de Boletins de Dados Técnicos (BDT) nas esferas competentes }\left(^{*}\right) \\
\text { 8. Criação de parâmetros e análise de custos do empreendimento e da sua viabilidade } \\
\text { financeira }\left(^{*}\right) \\
\text { 9. Assessoria quanto à análise e definição da tecnologia construtiva }\left(^{*}\right) \\
\text { 10. Levantamento de demanda ou pesquisa de mercado para o produto }\left(^{*}\right) \\
\text { 11. Assessoria ao empreendedor para aquisição de terrenos ou imóveis }\left(^{*}\right)\end{array}$ \\
\hline $\begin{array}{l}\text { Desenvolvimento do } \\
\text { Produto }\end{array}$ & $\begin{array}{l}\text { 12. Identificação e planejamento das fases de desenvolvimento do projeto } \\
\text { 13. Coordenação do fluxo de informações entre os agentes envolvidos } \\
\text { 14. Identificação e análise crítica das interfaces de projeto a serem solucionadas } \\
\text { 15. Validação de produtos de projeto e liberação para início das fases subseqüentes } \\
\text { 16. Aprovação de memoriais descritivos do produto, maquetes, apartamento modelo, } \\
\text { plantas e estande de vendas } \\
\text { 5. Organização, realização e registro de reuniões de coordenação de projetos } \\
\text { 17. Controle do processo quanto ao tempo e demais recursos } \\
\text { 18. Consulta a órgãos técnicos públicos e roteirização de aprovações legais do projeto } \\
\left({ }^{*}\right) \\
\text { 19. Definição de subsistemas e métodos construtivos e análise de alternativas } \\
\text { tecnológicas }\left({ }^{*}\right) \\
\text { 20. Estabelecimento de diretrizes tecnológicas para execução }\left(^{*}\right)\end{array}$ \\
\hline $\begin{array}{l}\text { Formalização do } \\
\text { Produto }\end{array}$ & $\begin{array}{l}\text { 13. Coordenação do fluxo de informações entre os agentes para desenvolvimento das } \\
\text { partes do projeto } \\
\text { 21. Análise crítica e tomada de decisões sobre as necessidades de integração das } \\
\text { soluções } \\
\text { 22. Análise das soluções técnicas e do seu grau de satisfação frente ao Programa de } \\
\text { Necessidades } \\
\text { 5. Organização, realização e registro de reuniões de coordenação de projetos } \\
\text { 15. Validação de produtos de projeto e liberação para início das fases subseqüentes } \\
\text { 17. Controle do processo quanto ao tempo e demais recursos } \\
\text { 23. Avaliação de indicadores de projeto }\left(^{*}\right)\end{array}$ \\
\hline Detalhamento & $\begin{array}{l}\text { 13. Coordenação do fluxo de informações entre os agentes intervenientes para } \\
\text { desenvolvimento das partes do projeto } \\
\text { 24. Análise crítica do detalhamento dos projetos } \\
\text { 5. Organização, realização e registro de reuniões de coordenação de projetos } \\
\text { 15. Validação de produtos de projeto e liberação para início das fases subseqüentes } \\
\text { 17. Controle do processo quanto ao tempo e demais recursos } \\
\text { 25. Avaliação do desempenho dos projetistas contratados } \\
\text { 26. Assessoria ao empreendedor para contratação da construtora }\left(^{*}\right)\end{array}$ \\
\hline $\begin{array}{l}\text { Planejamento e } \\
\text { Execução da Obra }\end{array}$ & $\begin{array}{l}\text { 27. Acompanhamento e avaliação do uso dos projetos no canteiro de obras e seus } \\
\text { eventuais ajustes } \\
\text { 28. Organização, realização e registro de reuniões de preparação da execução da obra* }\end{array}$ \\
\hline $\begin{array}{l}\text { Pós-entrega do } \\
\text { Empreendimento }\end{array}$ & $\begin{array}{l}\text { 29. Avaliação pós-ocupação e adequação do edifício a parâmetros de desempenho e } \\
\text { manutenção } \\
\text { 30. Organização, realização e registro de reuniões de avaliação e retroalimentação }{ }^{*} \text { ) }\end{array}$ \\
\hline \multicolumn{2}{|c|}{$\begin{array}{c}\text { (*) representa as atividades que podem ser necessárias ou não, dependendo do empreendimento, das } \\
\text { exigências do cliente ou da divisão de responsabilidades entre agentes }\end{array}$} \\
\hline
\end{tabular}

QUADRO 1: Atividades de coordenação em cada fase. Fonte: Adaptado de Melhado et al (2005). 
3.3 Práticas e Ferramentas de Apoio para a Coordenação de Projetos

Segundo Manso (2003, p.7), "existe a necessidade de se adotar procedimentos formais para a coordenação e integração dos projetos (...)". Esses procedimentos formais podem ser tratados como as práticas ${ }^{1}$ e ferramentas ${ }^{2}$ gerenciais de apoio à integração entre especialistas e coordenação de projetos.

Assim sendo, ferramenta, aqui adotada, quer dizer quais instrumentos que aliados à prática (modo de fazer) podem facilitar o processo de coordenação de projetos. Portanto, as práticas aliadas às ferramentas gerenciais resultam nas atividades de coordenação de projetos.

No QUADRO 2 estão relacionadas as práticas e as suas ferramentas de apoio.

Essas práticas são decorrentes das atividades atribuídas à coordenação de projetos, pois, como visto anteriormente, para a realização da coordenação de projetos são necessárias algumas atividades e a partir do modo de execução dessas atividades é que surgem as práticas, o modo de fazer.

Observa-se que a coluna das práticas está relacionada com a coluna das ferramentas; isso se deve ao fato de que essas ferramentas são instrumentos de apoio para as práticas correspondentes, ou seja, elas ajudam a organizar e controlar as atividades desenvolvidas ao longo do processo de projeto.

\begin{tabular}{|c|c|}
\hline PRÁTICAS & FERRAMENTAS DE APOIO \\
\hline - Preparação e Documentação do Projeto & $\begin{array}{l}\text { - } \quad \text { Padronização do Desenho } \\
\text { - } \quad \text { Reunião de Preparação }\end{array}$ \\
\hline - Planejamento do Processo de Projeto & $\begin{array}{ll}\text { - } & \text { Cronograma } \\
\text { - } & \text { Checklist de Validação das Fases de Projeto } \\
\text { - } \quad \text { Reunião de Planejamento }\end{array}$ \\
\hline - Compatibilização de Projetos & $\begin{array}{l}\text { - } \quad \text { Sobreposição de Projetos } \\
\text { - } \quad \text { Checklist de Verificação de Projetos } \\
\text { - } \quad \text { Reunião de Compatibilização }\end{array}$ \\
\hline - Comunicação e Reuniões & $\begin{array}{l}\text { - } \quad \text { Extranet } \\
\text { - } \quad \text { Reuniões de Reunião } \\
\text { - }\end{array}$ \\
\hline
\end{tabular}

QUADRO 2 - Práticas e ferramentas de apoio para a coordenação de projetos. Fonte: Bellan (2009) 
Analisando o QUADRO 2 é possível perceber que a reunião aparece tanto nas práticas como nas ferramentas; isso se deve ao fato de que é um elemento muito importante para a realização da coordenação, e esta pode assumir os dois papéis dependendo da situação.

\section{Estudo de Caso}

Esta seção apresenta uma síntese da descrição dos casos, elaborada a partir dos estudos desenvolvidos ${ }^{3}$.

\subsection{A Coordenação de Projetos na Empresa "A"}

A construtora, objeto de estudo, atua, principalmente, na construção de edifícios residenciais e possui um departamento interno de coordenação de projetos, no qual o planejamento do processo de projeto é definido e controlado; é nele também que os diferentes projetos das diferentes especialidades envolvidas no processo de projeto são coordenados e compatibilizados com uma equipe própria.

A empresa terceiriza seus projetos, isto é, não possui uma equipe interna de projetistas, mas possui uma cartela de parceiros que lhe prestam serviço, então esses parceiros remetem seus respectivos projetos para a empresa que os coordena e compatibiliza para depois emiti-los à equipe da obra.

Essa opção se dá por acreditar na agilidade que tal procedimento proporciona à empresa, visto que, os parceiros têm um prazo apertado e rigoroso. Essa exclusividade não seria possível se a equipe fosse interna a empresa, pois esta trabalha com diferentes empreendimentos ao mesmo tempo, o que demanda uma equipe muito grande de projetistas. A desvantagem dessa opção, apontada pela empresa é a diversidade de representações de desenhos apresentada pelos parceiros e, para solucionar tal problema, o desenho foi padronizado e exigido dos parceiros a utilização desse padrão da construtora, que é detalhado mais à frente.

A equipe de coordenação da construtora é formada pelo coordenador chefe, que coordena a equipe de coordenação de projetos e é responsável pela comunicação entre os diferentes setores que envolvem a realização do empreendimento (setor de marketing, financeiro, de vendas, de compras e de obras). Subordinado ao coordenador chefe (nível 
gerencial) há dois coordenadores (que podem ser caracterizados como nível tático) que planejam e controlam o processo de projetos dos empreendimentos da empresa, cada um responde, em média, por oito empreendimentos simultaneamente, sendo que cada empreendimento conta com um arquiteto compatibilizador de projetos (nível operacional), responsável pelas verificações e validações das fases de projeto. Cada arquiteto compatibilizadorresponde por até dois empreendimentos simultaneamente. Desta forma, a equipe de coordenação da empresa responde por até dezesseis empreendimentos distintos, simultaneamente.

A empresa acredita que com uma equipe interna, que conhece a cultura construtiva da empresa, as análises e as soluções são mais eficientes e que essas soluções têm mais chances de se tornarem banco de dados e aprendizado para evitar erros em outros empreendimentos. Pensando dessa maneira, a empresa arquiva toda análise e refinamento feito nas diferentes fases e especificidades do projeto.

\subsubsection{Fases de Projeto e Atividades de Coordenação}

A coordenação para a Empresa "A" está dividida da seguinte forma com suas respectivas atividades de coordenação, conforme QUADRO 3.

Na fase Concepção do Empreendimento o projeto do empreendimento chega ao departamento de coordenação já definido, isto é, já foi feita a pesquisa de mercado, o terreno já foi adquirido, o projeto legal já foi aprovado nos órgãos competentes, o lançamento para o público já foi feito e o imóvel já está disponível para compra.

A hora agora é de planejar o seu desenvolvimento e sua execução; sendo assim, o departamento de coordenação define as fases do projeto, as suas atividades correspondentes e elabora um cronograma de execução dos projetos das diferentes especialidades envolvidas no projeto do empreendimento.

A empresa possui um modelo de cronograma que sofre adaptações a cada novo empreendimento. Esse cronograma é elaborado no programa MSProject ${ }^{\circ}$. No cronograma são estabelecidos prazos para cada fase do projeto e, em cada fase, são definidas as datas para cada atividade. Neste caso é a coordenadora que controla os prazos, monitorando cada projetista parceiro. Reuniões são pré-estabelecidas para o término de cada fase, assim é desenvolvido um relatório do andamento do projeto, o que permite à coordenadora chefe acompanhar os projetos. Quando um prazo não é cumprido, são feitas reuniões extraordinárias para solucionar os problemas. As reuniões convencionais são previamente 
agendadas e, para elas, são convocados todos os envolvidos no projeto. Já nas reuniões extraordinárias são convocados somente os projetistas que não cumpriram o prazo e estas são sempre coordenadas pela coordenadora chefe e pela coordenadora responsável pelo empreendimento.

\begin{tabular}{|c|c|}
\hline FASES DE PROJETO & ATIVIDADES DE COORDENACÃO \\
\hline $\begin{array}{l}\text { Concepção do } \\
\text { Empreendimento }\end{array}$ & 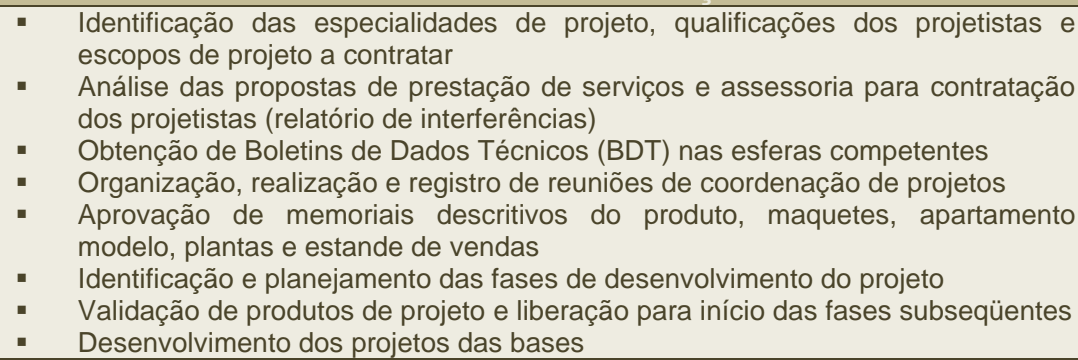 \\
\hline $\begin{array}{l}\text { Fase I: Emissão das } \\
\text { Bases }\end{array}$ & $\begin{array}{l}\text { - } \quad \text { Coordenação do fluxo de informações entre os agentes envolvidos } \\
\text { - } \quad \text { Identificação e análise crítica das interfaces de projeto a serem solucionadas } \\
\text { - } \quad \text { Controle do processo quanto ao tempo e demais recursos }\end{array}$ \\
\hline $\begin{array}{l}\text { Fase II: Condição de } \\
\text { Liberação para a Obra }\end{array}$ & 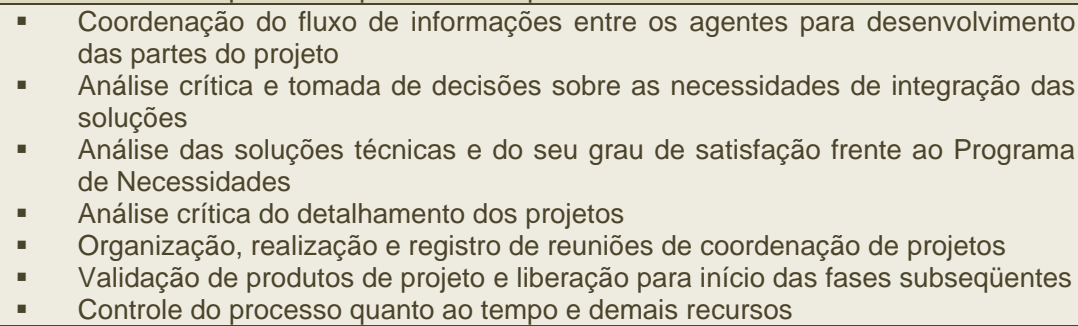 \\
\hline $\begin{array}{l}\text { Fase III: Emissão dos } \\
\text { Projetos para a Obra }\end{array}$ & $\begin{array}{l}\text { - Coordenação do fluxo de informações entre os agentes intervenientes para } \\
\text { desenvolvimento das partes do projeto } \\
\text { - } \quad \text { Organização, realização e registro de reuniões de coordenação de projetos } \\
\text { - } \quad \text { Validação de produtos de projeto e liberação para início das fases subseqüentes } \\
\text { - } \quad \text { Avaliação do desempenho dos projetistas contratados }\end{array}$ \\
\hline $\begin{array}{l}\text { Pós-entrega dos } \\
\text { Projetos Executivos }\end{array}$ & $\begin{array}{l}\text { - Acompanhamento e avaliação do uso dos projetos no canteiro de obras e seus } \\
\text { - } \quad \text { Orgentuais ajustes } \\
\text { obra (reunaãa de apresentação do projeto) }\end{array}$ \\
\hline $\begin{array}{l}\text { Desenvolvimento dos } \\
\text { Projetos para Produção }\end{array}$ & Validação de produtos de projeto e liberação para início das fases subseqüentes \\
\hline $\begin{array}{l}\text { Pós-entrega dos } \\
\text { Projetos para Produção }\end{array}$ & $\begin{array}{l}\text { - Acompanhamento e avaliação do uso dos projetos no canteiro de obras e seus } \\
\text { eventuais ajustes } \\
\text { - Organização, realização e registro de reuniões de preparação da execução da } \\
\text { obra (reunião de apresentação do projeto) }\end{array}$ \\
\hline
\end{tabular}

QUADRO 3: Fases de projeto e suas respectivas atividades de coordenação, na empresa "A". Fonte: Elaborado com base em dados fornecidos pela empresa "A" - Bellan (2009).

O cronograma é dividido em fases que são comuns para todos os empreendimentos, criando uma "espinha dorsal" de tarefas, contudo, cada empreendimento é único e essas especificidades são acrescentadas a essa "espinha dorsal" e controladas no cronograma.

Na Fase I: Emissão das Bases a empresa optou por dividir os projetos em: "tipo para cima" e "térreo para baixo", para facilitar a análise das pranchas. Pavimento Tipo é o que se 
repete várias vezes, desta forma, a nomenclatura "tipo para cima" significa que todos os pavimentos se repetem, mais a cobertura. Pavimento Térreo é o pavimento da implantação do edifício no terreno, desta forma, a nomenclatura "térreo para baixo" engloba o pavimento térreo mais todos os subsolos existentes.

A arquitetura é o desenho base para outros projetistas, só mostra a alvenaria - o contorno do edifício, os nomes de cada cômodo, indica as áreas molhadas e os caixilhos em plantas, cortes e fachadas. Essa base é feita no programa AutoCad $\circledast$ e é transmitida para os demais projetistas envolvidos no projeto do empreendimento em arquivo eletrônico.

São acrescentados ao desenho da arquitetura, os desenhos das diferentes especialidades envolvidas no projeto do empreendimento que são: paisagismo, impermeabilização, estrutura, fundação, segurança, arquitetura de interiores, instalações elétricas, instalações hidráulicas, ar condicionado e ventilação mecânica. Todos esses desenhos são enviados ao departamento de coordenação para serem compatibilizados entre si e, após essa fase, seguem para a fase seguinte.

Na Fase II: Condição de Liberação para a Obra todos os desenhos, descritos no item anterior, são compatibilizados e analisados, quando uma interferência é apresentada sua correção é solicitada aos projetistas responsáveis.

Na Fase III: Emissão de Projetos para a Obra os desenhos já revisados e corretos geram novas pranchas e se não apresentarem mais interferências entre si e necessitarem de correções, por parte dos projetistas, são encaminhadas ao departamento de execução de obras.

$\mathrm{Na}$ fase de Pós-entrega dos Projetos Executivos os desenhos de arquitetura, estrutura, arquitetura de interiores, instalações elétricas e hidráulicas, ventilação mecânica e ar condicionado, paisagismo e segurança são apresentados para o departamento de execução de obras e é feita uma última análise dos projetos e eventuais ajustes. Daí os projetos saem diretamente para o canteiro de obras.

Na fase de Desenvolvimento dos Projetos para Produção são desenvolvidos os projetos para produção de armação dos subsolos, térreo e do $1^{\circ}$ pavimento para cima, os projetos de forma de madeira, vedação e impermeabilização.

$\mathrm{Na}$ fase de Pós-entrega dos Projetos para Produção conforme mencionado anteriormente, os desenhos são apresentados ao departamento de execução e é feita uma última análise dos projetos e eventuais ajustes. De onde irão diretamente para o canteiro de obras. 
Para o controle do cronograma e dos prazos estabelecidos são feitas reuniões, uma em cada fase, com os projetistas envolvidos no empreendimento, com exceção da Fase I que contempla mais reuniões. Quando acontece algo emergencial são feitas reuniões especificas.

Outra particularidade da coordenação na empresa, objeto de estudo é o Relatório de

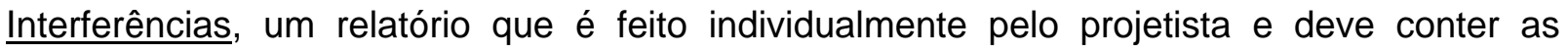
interferências previstas e ocorridas com as demais especialidades do empreendimento. Assim, o relatório de interferência de hidráulica deve conter a interferência dessa especialidade com a estrutura, por exemplo. Desse modo fica mais fácil controlar se os projetistas estão fazendo a análise dos seus projetos e minimizando os erros. A elaboração dos relatórios é acordada na assinatura do contrato de prestação de serviços e é muito importante para o controle das fases.

A análise desses relatórios é feita em reunião na Fase I e é pré-requisito para passar para a Fase II. Assim, quando os projetistas estão em reunião eles já resolvem pontualmente as interferências da sua especialidade com as dos demais, com a supervisão e orientação da coordenadora de projetos.

O departamento de coordenação da empresa não participa das atividades de pós entrega do empreendimento, somente elabora o manual do proprietário e arquiva os documentos gerados nas fases para servirem de banco de dados.

Foi possível verificar que o departamento de coordenação também não participa da definição do empreendimento, nem da parte financeira, isto é, compra e venda e nem da parte de execução, pois essas fases são responsabilidade de outros departamentos da empresa.

O departamento de coordenação é responsável, principalmente, por planejar, compatibilizar e controlar os prazos do projeto do empreendimento. Desta forma, são mostradas essas práticas e suas ferramentas respectivas, que são:

- Para planejamento das fases e controle dos prazos: cronograma e reuniões.

- Para a compatibilização dos desenhos: padronização dos desenhos e reuniões.

\subsubsection{Compatibilização dos Desenhos}

Os muitos parceiros apresentavam diferentes formas de desenhos e quando estes chegavam para a equipe de compatibilização, esta tinha uma grande dificuldade; a de praticamente refazer os desenhos para que todos ficassem com a mesma linguagem, isto é, a mesma representação gráfica. Tudo isso com: - geração de retrabalho; - aumento das 
horas gastas com projetos; - custo final do empreendimento, o que descontenta e compromete a eficácia da equipe de coordenação.

Para otimizar o trabalho e aumentar a eficiência da equipe de coordenação a empresa optou, efetivamente, por criar um padrão de desenho e repassá-lo para seus parceiros, explicado a seguir. O modelo criado não é complicado, mas no início da transição os parceiros fizeram reclamações. Segundo a coordenadora chefe da equipe, eles reclamaram porque a grande maioria já atua no mercado há muitos anos e tem o costume de fazer o desenho a sua maneira; o que significa que mudar para o padrão estabelecido pela empresa Ihes daria mais trabalho. Isso se deve, também, ao fato de que esses projetistas prestam serviço para várias empresas diferentes, sendo que cada empresa possui um padrão próprio, dessa forma, os projetistas precisam ficar adequando seus projetos aos diferentes padrões impostos pelas construtoras em que são parceiros.

A empresa desenvolveu seu próprio modelo com base na proposta da AsBEA (2005), para obter um padrão, uma vez que os parceiros, em sua maioria, não são exclusivos da empresa, dificultando a assimilação e o trabalho com o novo padrão da empresa, objeto de estudo.

Cabe ressaltar que a empresa não seguiu, exatamente, o modelo citado, pois preferiu utilizar sua própria nomenclatura para os arquivos seguindo o padrão dos arquivos dos demais departamentos da empresa. Isto, com a pretensão de criar uma uniformidade, uma linguagem comum para os arquivos da empresa e proporcionar um melhor armazenamento dos dados de cada empreendimento.

Contudo, passado o período de adaptação, os parceiros e a construtora acharam que o padrão ajudou e ainda ajuda muito na eficiência da compatibilização, pois agiliza o processo e diminui o tempo para fazer a sobreposição dos projetos e as devidas correções.

Quando a construtora inicia um novo empreendimento ela escolhe alguns de seus parceiros, levando em consideração o tipo de edifício a ser construído. Após essa fase esses projetistas são convocados para uma reunião e nessa reunião assistem à apresentação do projeto do empreendimento, definem as fases de projeto e recebem uma "cartilha" do padrão de desenhos da construtora. Vale salientar que essa cartilha é para desenhos feitos no computador, no programa AutoCad ${ }^{\circledR}$ e que a coordenação desses e o gerenciamento dos documentos e das informações são feitos pela ferramenta de extranet, com o programa SADP ${ }^{\circ}$. A referida cartilha contém uma apresentação ao parceiro do sistema de "bases" que 
a empresa utiliza; as bases são desenhos que só levam à especialidade do projetista (sua tarefa), por exemplo:

- Arquitetura Tipo para cima: alvenaria, layout, malha, caixilhos, nome dos ambientes, furo da coifa, forro, opções de plantas e tabela de níveis.

- Arquitetura Tipo para baixo: alvenaria, layout - exceto mobiliário de arquitetura de interiores, malha, caixilhos, nome dos ambientes e limite de terreno.

Cada escritório parceiro realiza uma base - um desenho base com as especificações do padrão da empresa - e esta é sobreposta às demais bases que podem vir a apresentar interferências.

Como exemplo se pode citar a base de estrutura com a base de hidráulica que, quando uma é sobreposta à outra o compatibilizador verifica se não há nenhuma interferência e se o desenho pode seguir para a obra.

\subsection{A Coordenação de Projetos na Empresa "B"}

A empresa possui um departamento interno de coordenação na matriz em Belo Horizonte e outro em cada regional, mas esses se reportam ao da matriz. Foi opção manter um departamento central e outros secundários nas regionais, porque a empresa acredita que assim pode controlar melhor o desenvolvimento dos projetos e assegurar a qualidade que a empresa tanto preza. Por se tratar de uma empresa dotada de "filiais" (regionais), esta apresenta uma estrutura hierárquica bem definida, com um bom fluxo de informações.

Na empresa a coordenação de projetos é desenvolvida no setor de desenvolvimento imobiliário. Esse setor tem um gerente nacional e cada regional tem um departamento de desenvolvimento imobiliário com: - um vice-presidente de desenvolvimento imobiliário; - duas gestoras, sendo uma de regularização de projetos e outra de incorporação; - três coordenadores, sendo um de regularização de projetos, um de incorporação e outro de desenvolvimento de projeto. O coordenador de desenvolvimento de projetos é responsável pela compatibilização de projetos e também por fomentar a comunicação entre os projetistas.

Os coordenadores das regionais mantêm um dialogo constante e direto com o gestor nacional da matriz, em Belo Horizonte. Desta forma a matriz tem o controle de todos os empreendimentos desenvolvidos nas regionais.

A equipe de coordenação de projetos da regional de Ribeirão Preto, onde foi realizado esse estudo, também tem que se reportar à equipe de coordenação da matriz, pois como a 


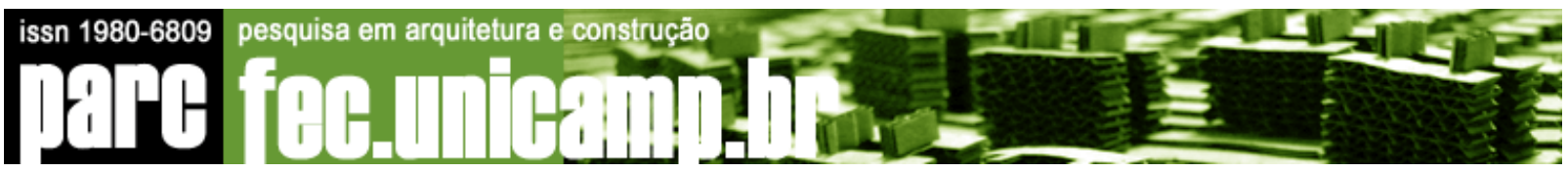

empresa trabalha com um padrão de construção, cada regional tem que se adequar a esse modelo.

\subsubsection{Fases de Projeto e Atividades de Coordenação}

A coordenação na Empresa "B" está dividida com suas respectivas atividades de coordenação, conforme mostra o QUADRO 4:

\begin{tabular}{|c|c|}
\hline FASES DE PROJETO & ATIVIDADES DE COORDENAÇÃO \\
\hline Concepção & $\begin{array}{l}\text { - } \quad \text { Aquisição do terreno } \\
\text { - } \quad \text { Obtenção de Boletins de Dados Técnicos (BDT) nas esferas competentes } \\
\text { - } \quad \text { Identificaçãão e planejamento das fases de desenvolvimento do projeto } \\
\text { - } \quad \text { Validação de produtos de projeto e liberação para início das fases subseqüentes }\end{array}$ \\
\hline Fase I & $\begin{array}{l}\text { - } \quad \text { Contratação dos profissionais das diferentes especialidades } \\
\text { - } \quad \text { Identificaçãão e análise crítica das interfaces de projeto a serem solucionadas } \\
\text { - } \quad \text { Organização, realização e registro de reuniões de coordenação de projetos }\end{array}$ \\
\hline Fase II & 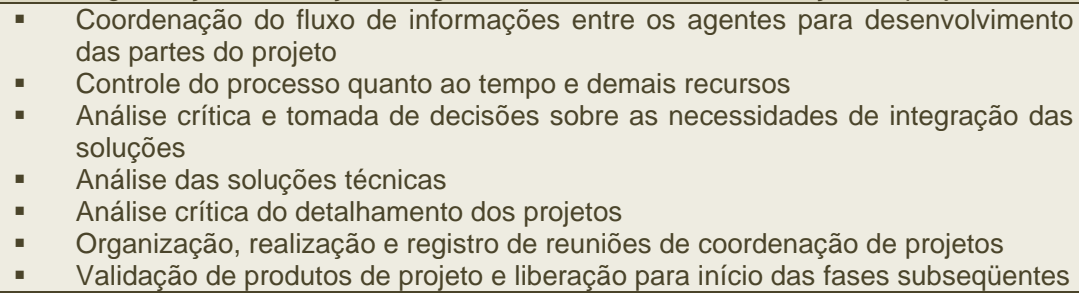 \\
\hline Fase III & $\begin{array}{l}\text { - Coordenação do fluxo de informações entre os agentes intervenientes para } \\
\text { desenvolvimento das partes do projeto } \\
\text { - } \quad \text { Organização, realização e registro de reuniões de coordenação de projetos } \\
\text { - } \quad \text { Contidação de produtos de projeto e liberação para início das fases subseqüentes } \\
\text { Controcesso quanto ao tempo e demais recursos }\end{array}$ \\
\hline Pós-ent & o de problemas legais ou reprovação na obra. \\
\hline
\end{tabular}

QUADRO 4: Fases de projeto e suas respectivas atividades de coordenação, na empresa "B"

Fonte: Elaborado com base em dados fornecidos pela empresa "B" - Bellan (2009).

$\mathrm{Na}$ fase da Concepção para o lançamento de um empreendimento, a regional escolhe o terreno, viabiliza a documentação na prefeitura local e identifica a demanda do tipo do empreendimento na cidade em que este vai ser inserido, isto é, o número de quartos, a área de lazer, se haverá ou não, o que terá na área do condomínio, se será edifício (até quatro pavimentos) ou torre (de cinco a oito pavimentos) etc, isto é, elabora o programa de necessidade. Essas informações são passadas para a matriz que determina qual o projeto padrão da empresa será utilizado e manda para a regional.

Na Fase I a regional recebe o estudo do projeto e a partir deste ponto inicia sua coordenação de projetos, isto é, contrata os parceiros para as diferentes especialidades e Ihes solicita os projetos específicos. 
A empresa trabalha com projeto padrão, isto é, quando se define que a unidade do empreendimento terá dois quartos, por exemplo, o profissional da arquitetura terá que trabalhar dentro do padrão de solução da empresa e o desenho deverá seguir as exigências e as determinações estabelecidas pela empresa, que são sempre as mesmas para cada tipo de empreendimento.

Esse padrão de solução determina as medidas dos ambientes (quartos, sala, banheiro e cozinha) e em alguns casos determina também a aparência das unidades, estabelecendo uma tipologia para fachada e tipo de acabamentos. Podemos ilustrar esse procedimento como um "catálogo de projetos", que para cada tipo de empreendimento a ser lançado tem um modelo a ser seguido. As adaptações desse padrão são feitas sob supervisão do coordenador, que dentro do padrão proposto da empresa, julgará a necessidade e viabilidade das mudanças.

$\mathrm{Na}$ Fase II os projetos, das diferentes especialidades, são elaborados e encaminhados para a coordenação da regional que verifica se estão de acordo com as diretrizes e exigências do empreendimento para compatibilizá-los.

Na Fase III todo projeto do empreendimento, depois de compatibilizado é remetido à coordenação da matriz para aprovação e, após essa aprovação, é disponibilizado para a equipe de execução, para o departamento de engenharia e projeto executivo.

$\mathrm{Na}$ fase de Pós-entrega o departamento de desenvolvimento de projetos não acompanha a obra; só é solicitado quando há problemas políticos ou legais ou mesmo quando há reprovação. Auxilia no "habite-se" e na instituição do condomínio. Os documentos gerados são encaminhados para um setor de manutenção que cria um banco de dados.

A coordenação de projetos na regional é responsável, principalmente, pelo fluxo de informações e compatibilização dos projetos. É ela que viabiliza os projetos para a execução e faz a "ponte" com a matriz para o lançamento do empreendimento local.

Sendo assim, o destaque nas atividades de coordenação é dado para o controle do fluxo de informação, o controle dos prazos e a compatibilização de projetos. Desta forma, este estudo na empresa "B" se atém em mostrar essas práticas e suas respectivas ferramentas, que são:

- Para o controle do fluxo de informações e dos prazos: cronograma, troca de emails, reuniões, contratos e regularização da documentação.

- Para a compatibilização dos desenhos: padronização dos desenhos, reuniões e troca de arquivos entre os setores. 
4.2.2 Controle do Fluxo de Informações e dos Prazos

Como o departamento da filial precisa se reportar ao departamento da matriz, a comunicação se torna essencial e é o coordenador o responsável pela troca de informações, por criar um fluxo de informações, "filtrando" o que deve ser informado para os envolvidos no empreendimento.

A empresa não utiliza nenhum programa computacional em especial, somente trocam e-mails e, como tudo passa pela coordenadora, ela consegue controlar os prazos e distribuir as informações necessárias para cada projetista envolvido no processo do projeto, assim como os demais membros da equipe da empresa. A coordenadora é responsável por toda a troca de informações do empreendimento.

O cronograma do projeto apresenta prazos curtos, e como a coordenação participa desde a compra do terreno até o habite-se, este é rigorosamente cumprido. Se, por algum motivo, um prazo é adiado deve ocorrer uma reunião extraordinária, pois o cronograma não prevê muitas reuniões, somente uma no início para apresentar o empreendimento e outra na final para apresentá-lo à equipe da obra.

\subsubsection{Compatibilização dos Desenhos}

Como o projeto já vem estabelecido pela matriz, a empresa utiliza um padrão de solução para cada tipo de empreendimento, variando entre, padrão de 3 quartos, 2 quartos, simples e simples SP (nomenclatura dada pela empresa). Além desse padrão há, ainda, a divisão por tipologia, número de pavimento e principalmente número de unidade por bloco, bem como elementos usados nas fachadas e tipo de acabamentos.

A empresa tem uma carteira de profissionais, por regional, para cada padrão a ser construído, desta forma, o coordenador faz o contato com os parceiros e estes obedecem a "cartilha", que contém as diretrizes para a elaboração de cada projeto dentro dos padrões da empresa. $\mathrm{Na}$ "cartilha" há o registro das principais diretrizes para a elaboração do desenho e, como a empresa utiliza um modelo para casa, edifícios e torres, esse padrão detalha vários aspectos do desenho, tais como: - identificação e versão de projeto, - formato das folhas, carimbo, - implantação, - esquadrias, - pavimento tipo, - cômodos privativos, - cômodos comuns, - cortes, - compatibilização com engenharia (pilares e pé-direito), - cotas, - alvenaria e - vagas da garagem.

Segundo o coordenador da empresa, a padronização utilizada facilita muito na hora de compatibilizar e checar os desenhos das diferentes especialidades de projeto. A empresa 
também utiliza um checklist juntamente com a "cartilha" para verificar a regularidade dos projetos. O checklist juntamente com a padronização do desenho aceleram o processo de verificação, que, para a coordenadora, é muito importante, pois o cronograma é muito curto, não disponibilizando muitos dias para cada tarefa.

\subsection{Análise dos Estudos de Caso}

Fazendo uma análise dos estudos de caso, pode-se observar que ambas utilizam processo de projeto, com nomes distintos, mas as atividades são bem similares àquelas apresentadas no QUADRO 1, intitulado "Atividades de coordenação em cada fase", adaptado de Melhado et al (2005).

Notou-se que cada empresa tem suas particularidades como segue.

- Empresa "A": O projeto chega ao departamento de coordenação com o programa de necessidades traçado e o anteprojeto pronto. A coordenação assume as fases Detalhamento do Produto, Planejamento para Produção e Entrega Final, sendo que nessa última só arquiva as soluções e monta um banco de dados para ajudar nas atividades dos empreendimentos futuros.

- Empresa "B": O programa de necessidades e o projeto são enviados da matriz para as regionais e nessas são desenvolvidos. Dessa forma, o departamento de desenvolvimento imobiliário (responsável pela coordenação de projetos) de cada regional fica responsável pelas fases Idealização do Produto, Desenvolvimento do Produto, Formalização do Produto e Detalhamento do produto. Não atuam no planejamento e execução da obra, nem na pós-entrega do empreendimento, sendo que nesta última somente atua na obtenção do habite-se.

\subsubsection{Atividades de Coordenação}

Para uma análise mais detalhada do estudo nas duas empresas foi elaborado um quadro comparativo entre as atividades de coordenação nas empresas (QUADRO 5). 


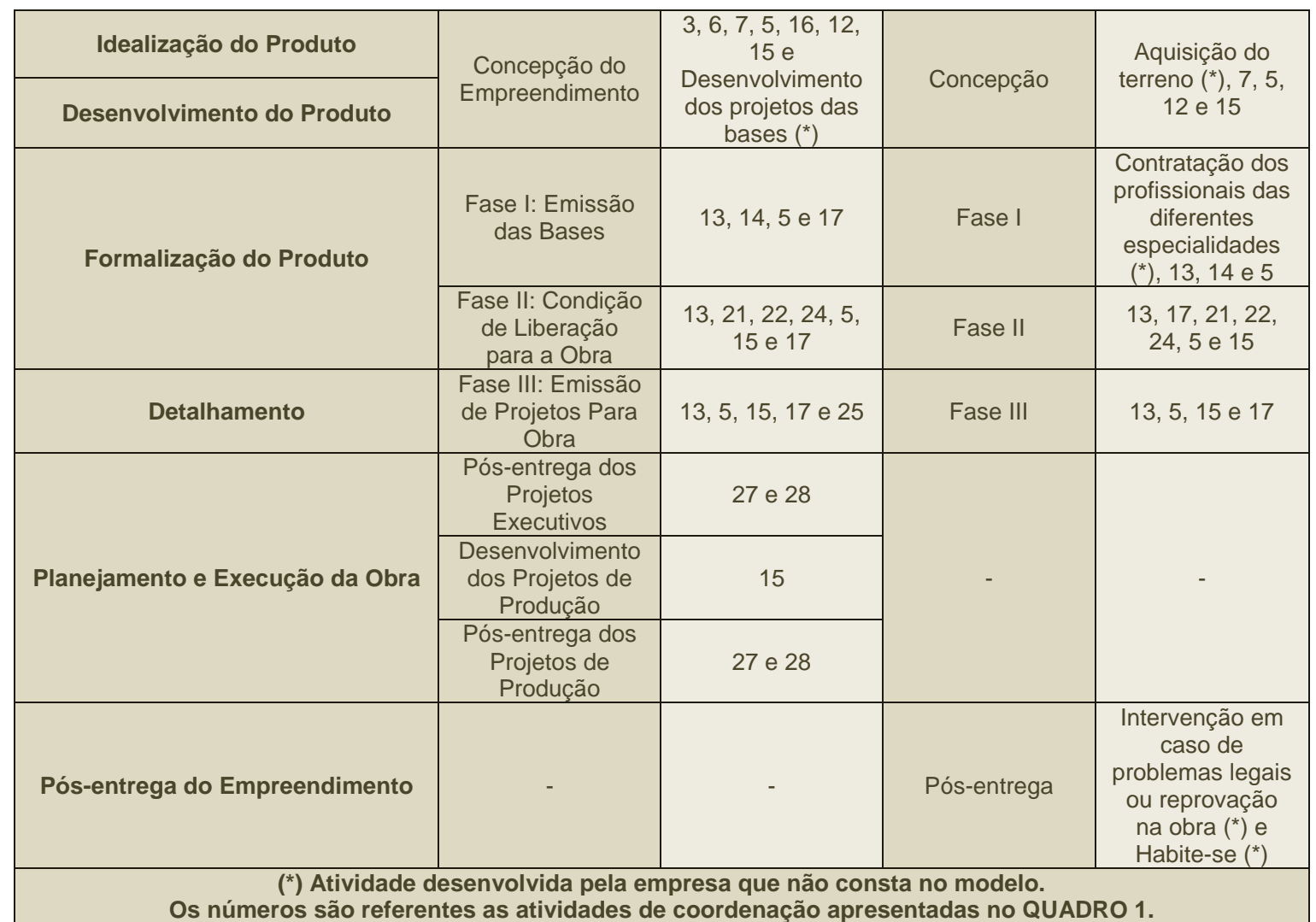

QUADRO 5 : Atividades de coordenação de projetos nas empresas "A" e "B". Fonte: Elaborado com base em informações e documentos fornecidos pelas empresas "A" e "B" - Bellan (2009).

Analisando o QUADRO 5 podemos observar que as atividades, abaixo relacionadas, são realizadas pelas duas empresas nas mesmas fases:

- 5 - Organização, realização e registro de reuniões de coordenação de projetos.

- 7 - Obtenção de Boletins de Dados Técnicos (BDT) nas esferas competentes.

- 12 - Identificação e planejamento das fases de desenvolvimento do projeto.

- 13 - Coordenação do fluxo de informações entre os agentes envolvidos.

- 14 - Identificação e análise crítica das interfaces de projeto a serem solucionadas.

- 15 - validação de produtos de projetos e liberação para início das fases subseqüentes.

- 17 - Controle do processo quanto ao tempo e demais recursos.

- 21 - Análise crítica e tomada de decisões sobre necessidades de integração das soluções.

- 22 - Análise das soluções técnicas e do seu grau de satisfação frente ao programa de necessidades. 
- 24 - Análise crítica do detalhamento do projeto

Na empresa "A", o departamento de coordenação não participa da pós-entrega do empreendimento, pois possui um departamento para tal fase, já a empresa "B" participa desta fase auxiliando no habite-se e intervindo em casos de problemas legais; não participa da fase de planejamento e execução da obra, pois possui um departamento para essa fase.

Podemos observar também que a empresa "B" desenvolve mais atividades que não constam no modelo do que a empresa "A", pois a coordenação na empresa "B" é desenvolvida conjuntamente entre matriz e regional ou vice-versa.

Como resultado da análise, evidenciamos que, mesmo apresentando um nome diferente, ou se apresentando em diferentes fases, as atividades de coordenação apresentadas no QUADRO 1 são comuns as duas empresas.

\subsubsection{Práticas e Ferramentas de Apoio}

Para ilustrar e comparar a utilização das práticas e das ferramentas analisadas nos estudos foi elaborado uma comparação entre as práticas e ferramentas de apoio observadas nos estudos e realizadas segundo classificações apontadas pela literatura (QUADRO 2). É também identificado para cada prática o responsável pela sua execução.

Analisando o QUADRO 6 podemos observar que a empresa "A" utiliza as ferramentas de apoio estudadas menos a reuniões virtuais e que a empresa "B" não utiliza a reunião de compatibilização, extranet e reuniões virtuais.

A empresa "B" não utiliza a reunião de compatibilização, pois esta é realizada na regional pela coordenadora e enviada por e-mail para a matriz aprovar as possíveis modificações ocorridas nos casos de interferências entre projetos. Para o uso de extranet, a empresa "B" tem opção por utilizar o e-mail do servidor da empresa e se o problema for urgente ou muito complicado de ser resolvido, fazem uso do telefone em uma conferência por telefone. As reuniões virtuais não são utilizadas nas empresas, mas ambas demonstraram interesse e consideraram que a ferramenta pode auxiliar e muito na troca de informações entre os agentes envolvidos no projeto que estão em diferentes localidades. Dessa forma a empresa "B" despertou um interesse maior por se tratar de uma regional e ter que se reportar a matriz que fica em Belo Horizonte. 


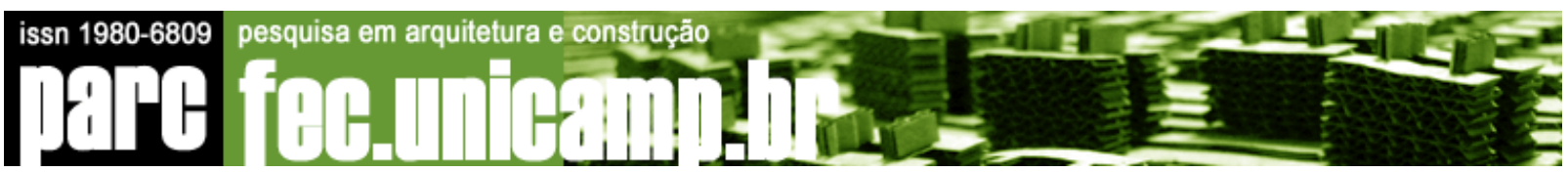

\begin{tabular}{|c|c|c|c|c|c|}
\hline Práticas & Ferramentas & Empresa "A" & Responsável & Empresa "B" & Responsável \\
\hline \multirow{2}{*}{$\begin{array}{l}\text { Preparação e } \\
\text { Documentação } \\
\text { do Projeto }\end{array}$} & $\begin{array}{l}\text { Padronização do } \\
\text { Desenho }\end{array}$ & $\begin{array}{l}\text { Cartilha, manual } \\
\text { que contem o } \\
\text { padrão de } \\
\text { representação } \\
\text { gráfica da } \\
\text { empresa } \\
\end{array}$ & Coordenador & $\begin{array}{l}\text { Cartilha, manual } \\
\text { que contem o } \\
\text { padrão de } \\
\text { representação } \\
\text { gráfica da } \\
\text { empresa } \\
\end{array}$ & Coordenador \\
\hline & $\begin{array}{l}\text { Reunião de } \\
\text { Preparação }\end{array}$ & $\begin{array}{c}\text { Realizada com } \\
\text { todos os } \\
\text { envolvidos no } \\
\text { projeto, apresenta } \\
\text { a cartilha }\end{array}$ & Coordenador & $\begin{array}{l}\text { Realizada com } \\
\text { projetistas } \\
\text { envolvidos no } \\
\text { empreendimen- } \\
\text { to, apresenta a } \\
\text { cartilha }\end{array}$ & Coordenador \\
\hline & & & & & \\
\hline \multirow{3}{*}{$\begin{array}{l}\text { Planejamento do } \\
\text { Processo de } \\
\text { Projeto }\end{array}$} & Cronograma & $\begin{array}{l}\text { Desenvolvido pela } \\
\text { coordenação e } \\
\text { norteia e controla } \\
\text { os prazos das } \\
\text { atividades }\end{array}$ & Coordenador & $\begin{array}{l}\text { Desenvolvido } \\
\text { pela coordena- } \\
\text { ção da regional } \\
\text { p/ controle dos } \\
\text { prazos } \\
\end{array}$ & Coordenador \\
\hline & $\begin{array}{l}\text { Checklist de } \\
\text { Validação das } \\
\text { Fases de } \\
\text { Projeto }\end{array}$ & $\begin{array}{l}\text { Desenvolvido pela } \\
\text { equipe de coorde- } \\
\text { nação, apresenta } \\
\text { elementos p/ } \\
\text { verificar as fases } \\
\text { de projeto }\end{array}$ & Coordenador & $\begin{array}{l}\text { Desenvolvido } \\
\text { pela equipe de } \\
\text { coordenação da } \\
\text { matriz, apresen- } \\
\text { ta elementos } \\
\text { para verificar as } \\
\text { fases de projeto }\end{array}$ & Coordenador \\
\hline & $\begin{array}{l}\text { Reunião de } \\
\text { Planejamento }\end{array}$ & $\begin{array}{l}\text { Realizada com } \\
\text { todos os projetis- } \\
\text { tas para apresen } \\
\text { tar o cronograma } \\
\text { e estabelecer os } \\
\text { prazos para a rea- } \\
\text { lização das ativi- } \\
\text { dades do projeto }\end{array}$ & Coordenador & $\begin{array}{l}\text { Realizada com } \\
\text { todos os proje- } \\
\text { tistas para apre- } \\
\text { sentar o crono- } \\
\text { grama, estabele- } \\
\text { cer os prazos à } \\
\text { realização das } \\
\text { atividades do } \\
\text { projeto }\end{array}$ & Coordenador \\
\hline & & & & & \\
\hline \multirow{3}{*}{$\begin{array}{l}\text { Compatibiliza- } \\
\text { ção de Projetos }\end{array}$} & $\begin{array}{l}\text { Sobreposição de } \\
\text { Projetos }\end{array}$ & $\begin{array}{l}\text { Os projetos são } \\
\text { sobrepostos uns } \\
\text { aos outros e } \\
\text { verificadas as } \\
\text { interferências } \\
\text { entre eles }\end{array}$ & Compatibilizador & $\begin{array}{l}\text { Os projetos são } \\
\text { sobrepostos uns } \\
\text { aos outros e } \\
\text { verificadas as } \\
\text { interferências } \\
\text { entre eles }\end{array}$ & Coordenador \\
\hline & $\begin{array}{l}\text { Checklist de } \\
\text { Verificação de } \\
\text { Projetos }\end{array}$ & $\begin{array}{l}\text { Desenvolvido pela } \\
\text { equipe de coorde- } \\
\text { nação, apresenta } \\
\text { elementos para } \\
\text { verificar possíveis } \\
\text { interferências } \\
\text { entre projeto }\end{array}$ & Compatibilizador & $\begin{array}{c}\text { Desenvolvido } \\
\text { pela equipe de } \\
\text { coordenação, } \\
\text { apresenta } \\
\text { elementos p/ } \\
\text { verificar Possi- } \\
\text { veis interfe- } \\
\text { rências entre } \\
\text { projeto }\end{array}$ & Coordenador \\
\hline & $\begin{array}{l}\text { Reunião de } \\
\text { Compatibiliza- } \\
\text { ção }\end{array}$ & $\begin{array}{l}\text { Os projetistas } \\
\text { apresentam o } \\
\text { relatório de } \\
\text { interferência e são } \\
\text { verificados os } \\
\text { pontos que } \\
\text { apresentarem } \\
\text { interferência }\end{array}$ & Coordenador & não & não \\
\hline
\end{tabular}

QUADRO 6: Quadro síntese das Práticas e Ferramentas de apoio nas empresas "A" e "B". Fonte:

Elaborado pela autora com base em informações e documentos fornecidos pelas empresas "A" e "B" -

Bellan (2009). 


\begin{tabular}{|c|c|c|c|c|c|}
\hline Práticas & Ferramentas & Empresa "A" & Responsável & Empresa "B" & Responsável \\
\hline \multirow[t]{3}{*}{$\begin{array}{c}\text { Comunicação e } \\
\text { Reuniões }\end{array}$} & $\begin{array}{l}\text { Atas de } \\
\text { Reuniões }\end{array}$ & $\begin{array}{l}\text { É realizada a cada } \\
\text { reunião e } \\
\text { disponibilizada } \\
\text { para todos os } \\
\text { envolvidos } \\
\text { tomarem } \\
\text { conhecimento das } \\
\text { ações tomadas na } \\
\text { reunião e é } \\
\text { arquivada com os } \\
\text { documentos do } \\
\text { empreendimento }\end{array}$ & Coordenador & $\begin{array}{c}\text { É realizada a } \\
\text { cada reunião e } \\
\text { disponibilizada } \\
\text { para todos os } \\
\text { envolvidos } \\
\text { tomarem } \\
\text { conhecimento } \\
\text { das ações } \\
\text { tomadas na } \\
\text { reunião e é } \\
\text { arquivada com } \\
\text { os documentos } \\
\text { do empreendi- } \\
\text { mento }\end{array}$ & Coordenador \\
\hline & Extranet & $\begin{array}{c}\text { A empresa utiliza } \\
\text { o SADP e cada } \\
\text { participante do } \\
\text { empreendimento } \\
\text { tem uma senha e } \\
\text { a troca de } \\
\text { informações é } \\
\text { controladas pelo } \\
\text { coordenador }\end{array}$ & Coordenador & não & não \\
\hline & $\begin{array}{l}\text { Reuniões } \\
\text { Virtuais }\end{array}$ & não & não & não & não \\
\hline
\end{tabular}

QUADRO 6 : [CONTINUAÇÃO] Quadro síntese das Práticas e Ferramentas de apoio nas empresas "A" e "B". Fonte: Elaborado pela autora com base em informações e documentos fornecidos pelas empresas "A" e "B" - Bellan (2009).

Na prática de Preparação e Documentação do Projeto verifica-se semelhanças entre os estudos de casos. Utiliza-se padronização do desenho por meio da divulgação e obediência a uma cartilha e manual explicativo que apresentam os padrões adotados de representação gráfica das empresas. Utiliza-se também reuniões de preparo que são realizadas com todos os envolvidos no projeto, onde a cartilha é apresentada. Esta prática é de responsabilidade do coordenador. A única variação observada está nos participantes da reunião de preparação, que pode se restringir aos projetistas envolvidos ou pode ser ampla e envolver todos os participantes do projeto.

\section{Considerações Finais}

A prática da Coordenação de Projetos é fundamental para integrar os projetistas e garantir o desenvolvimento integrado de novos produtos imobiliários. 
Cabe a coordenação de projetos garantir que os especialistas de projeto utilizem práticas de colaboração melhores e as mais rápidas soluções; de forma a transformar o projeto num processo interativo de acúmulo e aprimoramento de informações, diminuindo o retrabalho, o desperdício de tempo e recursos durante o projeto e de forma indireta, melhorando o desempenho das obras.

O presente trabalho demonstrou que a atividade de coordenação é desenvolvida para gerenciar cada fase do projeto e é auxiliada por ferramentas gerenciais que garantem a sua eficácia. Os estudos de caso em duas empresas de construção e incorporação de edifícios verificou que as empresas vêm utilizado práticas de coordenação condizentes com a litertura estudada e demonstram uma série de semelhanças nas práticas de coordenação de projetos das duas empresas (ver item 5).

As principais tarefas da coordenação verificas na literatura e presentes nos casos estudados são relacionadas ao planejamento do processo de projeto, a coordenação das soluções dos projetos desenvolvidos e compatibilização de desenhos e documentos de projeto.

Para que se tenha um bom desempenho da coordenação de projetos é necessário que o conhecimento do processo de projeto seja formalizado, para, assim, poder planejar as atividades de projeto e controlar o fluxo de informações entre os participantes.

Dessa forma, as atividades de coordenação são sistematizadas e se apresentam divididas em idealização do produto, desenvolvimento do produto, formalização do produto, detalhamento do produto, planejamento e execução da obra e pós-entrega do empreendimento.

Os casos reforçam a literatura sobre o tema quanto ao papel do coordenador de projetos. De fato, para guiar a equipe de projeto deve existir a figura do coordenador, com um perfil de líder que fomente o entrosamento dos participantes no processo de projeto.

Sendo assim, para que a coordenação garanta a qualidade do projeto ela necessita que as práticas de suas atividades tenham uma formalização o que não exclui a experiência e os conhecimentos tácitos do coordenador, pois de nada adianta padronizar os procedimentos e as práticas de coordenação se esse profissional não souber conduzir os participantes envolvidos no projeto.

Conforme as análises desenvolvidas no trabalho pode afirmar que às práticas de coordenação de projetos estão subordinadas ferramentas gerenciais que facilitam o processo 
de coordenação e proporcionam ao coordenador instrumentos que facilitam "o modo de fazer" das atividades de coordenação.

Neste trabalho percebemos que, no estágio tecnológico atual do processo de projeto, a experiência do coordenador é muito importante, porque as ferramentas de apoio apresentam algumas limitações que obrigam o profissional a fazer um exercício de imaginação para alinhar os desenhos em duas dimensões (plantas e cortes, representada com auxílio de símbolos de projeto) à realidade da obra (que é tridimensional, real). É esse profissional quem se conecta com todos os demais profissionais envolvidos no empreendimento, tendo que lidar com falta de conhecimento técnico, no caso dos empresários empreendedores, desconhecimento do padrão e da cultura construtiva da empresa, no caso de novos parceiros projetistas de especialidade, e outras limitações que obrigam o coordenador de projetos usar sua experiência para suprir lacunas nos projetos de especialidades e entre estes.

Neste trabalho ilustramos a utilização de procedimento de coordenação e de ferramentas gerenciais de apoio. Embora esses procedimentos sejam diferentes para cada empresa, levando em conta suas particularidades, seu uso se mostrou fundamental para prática da coordenação de projetos e o trabalho apresenta referencias baseadas na análise da literatura e na prática de grandes empresas que podem subsidiar a montagem de procedimentos e ferramentas particulares para casos e empresas distintas.

\section{Referências}

AsBEA - Associação Brasileira dos Escritórios de Arquitetura. Manual de contratação dos serviços de Arquitetura e Urbanismo. 2. ed. São Paulo: Pini, 2000.

AsBEA - Associação Brasileira dos Escritórios de Arquitetura. Otimização e padronização de informações em CADD. São Paulo. 2005. CD-ROM.

BACK, N. et al. Projeto Integrado de Produtos: planejamento, concepção e modelagem. São Paulo: Manole, 2008.

MACHADO, M.C., TOLEDO, N.N. Gestão do Processo de Desenvolvimento de Produtos. São Paulo: Atlas, 2008.

BELLAN, M. Práticas e ferramentas para coordenação de projetos de edifícios. 2009. Dissertação (Mestrado). Escola de Engenharia de São Carlos - USP, São Carlos - SP. 
COATES, G.; DUFFY, A. H. B.; WHITFIELD, I.; HILLS, W. Engineering management: operational design coordination. Journal of Engineering Design. Vol. 15, No 5. October, 2004. 443-446.

FABRICIO, M. M. . Desenvolvimento de produtos e inovações produtivas em empresas de construção de edifícios. Produto \& Produção, v. 10, p. 121-138, 2009.

FABRICIO, M. M. Projeto Simultâneo na Construção de Edifícios. 2002. Tese (Doutorado) - Escola Politécnica da USP, São Paulo.

FRANCO, L. S.; AGOPYAN, V. Implementação da racionalização construtiva na fase de Projeto. Boletim Técnico da Escola Politécnica da USP - Departamento de Engenharia Civil. São Paulo, 1993.

HOUAISS, Antonio e VILLAR, Mauro de Salles. Minidicionário Houaiss da língua portuguesa. 2. ed. rev. e aum. Rio de Janeiro: Objetiva, 2004.

MANSO, M.A. Ferramentas para coordenação e integração de projetos para o setor imobiliário. In: WORKSHOP NACIONAL DE GESTÃO DO PROJETO DE PROCESSO NA CONSTRUÇÃO DE EDIFÍCIOS, 3., 2003, Belo Horizonte. Anais ... Belo Horizonte: UFMG, 2003.

MELHADO, S.B. (coord.); SOUZA, A.L.R. de; FONTENELLE,E.; AQUINO, J.; GRILO, L.; FRANCO, L. S.; MESQUITA, M. J.; PEŇA, M. D.; FABRICIO, M. M.; OLIVEIRA, O. J. Coordenação de projetos de edificações. São Paulo: O Nome da Rosa, 2005.

ROMANO, F. V. Modelo de referência para o gerenciamento do processo de projeto integrado de edifícios. 2003. Tese (Doutorado), Universidade Federal de Santa Catarina, Florianópolis.

ROZENFELD, H. et al. Gestão do desenvolvimento de produtos: Uma referência para a melhoria do processo. São Paulo: Saraiva, 2006.

TAHON, C. Le pilotage simultané d'un projet de construction. Paris: Collection Recherche, 1997.

SARAM, D. de; AHMED, S.M. Construction coordination activities: what is important and what consumes time. Jounarl of management in engineering. Outubro de 2001. p. 202-213.

TZORTZOPOULOS, P. The design implementation of product development process models in construction companies. 2004. Tese (PhD) - University of Salford, UK, Salford.

ULRICH, K.T., EPPINGER, S.D. Product design and development. Boston: McGrawHill/Irwin, 2004. 


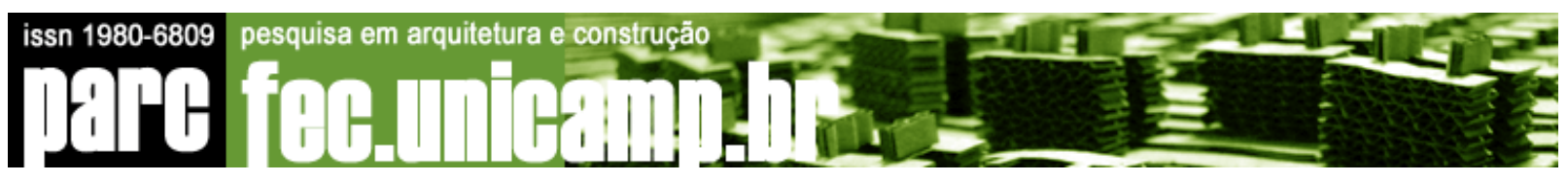

\section{Notas}

${ }^{1}$ De acordo com o Minidicionário Houaiss da Língua Portuguesa (2004, p.588), Prática: 1. Ação, execução, exercício. 2. Realização concreta de uma teoria. 3. Capacidade que resulta da experiência. 4. Maneira usual de fazer ou agir; costume hábito.

${ }^{2}$ No mesmo Dicionário (2004, p.339) Ferramenta: 1. Utensílio que auxilia a execução de um trabalho artesanal ou mecânico. 2. Qualquer instrumento necessário à prática profissional. 3. Meio para alcançar um resultado.

${ }^{3}$ Estudos de caso desenvolvidos na dissertação de mestrado de Melissa Bellan (2009). 